\title{
The Quality of Nursing Service Management In South African Hospitals
}

\author{
Marie Muller \\ D.Cur. \\ Professor of Nursing \\ Rand Afrikaans University
}

"Quality refers to excellence within a given service and excellence is described by means of standards and criteria in accordance with the expectations of the different roleplayers - the patient, service providers and funders."

\begin{abstract}
The purpose of this study is to determine - explore and describe - the quality of nursing service management in South African hospitals. A combined qualitative and quantitative pre- and post-test research strategy, in accordance with the COHSASA programme, was utilised. The hospitals implement the national standards during the preparatory phase, after having entered into an agreement with COHSASA. They determine their baseline status by means of an assisted self-evaluation. This is followed by an external survey phase where the hospital's compliance with the standards is evaluated. The nursing service is one of the professional services included in the accreditation programme. Their performance is compared with selected other professional services and their compliance with the core elements is also evaluated. The nursing services in South Africa are compliant with the national standards. The deficiencies are mainly within the quality improvement programmes that require further development and refinement.
\end{abstract}

\section{Uittreksel}

Die doel met hierdie studie is om die gehalte van verpleegdiensbestuur van in Suid-Afrikaanse hospitale te bepaal - verken en beskryf. 'n Gekombineerde kwalitatiewe en kwantitatiewe voor- en na-toets navorsingstrategie, ingevolge COHSASA se akkrediteringsprogram, word nagevolg. Die betrokke hospitaal wat 'n ooreenkoms met COHSASA aangegaan het, implementeer die standaarde tydens die voorbereidingsfase. Die gesondheidsdiens bepaal hul basislynstatus met behulp van ge-assisteerde selfevaluering. Daarna volg ' $n$ eksterne evalueringsfase om die hospitaal se voldoening aan die standaarde te bepaal. Die verpleegdiens is een van die professionele dienste wat by die akkrediteringsprogram ingesluit is. Hul prestasie word vergelyk met enkele ander professionele dienste. Vervolgens is hul prestasie betreffende die kernelemente in die program beoordeel. Die verpleegdienste in Suid-Afrikaanse hospitale voldoen aan die nasionale standaarde. Die leemtes lê hoofsaaklik in die gehalteverbeteringsprogramme wat verdere ontwikkeling en verfyning benodig.

\section{Introduction}

Quality refers to excellence within a given service and excellence is described by means of standards and criteria in accordance with the expectations of the different role-players - the patient, service providers and funders. These standards can be structure, process or outcome-based. Compliance with standards can be evaluated by the service providers themselves in an informal manner, or within a formalised accreditation system. Accreditation is a process whereby national standards are set and compliance with them evaluated. Generic national standards are formulated by the professions and services at large, and implemented by the specific health care institutions or services, fol- lowed by an external evaluation by peers (Donahue \& O'Leary, 1997:128-132).

There are many factors impacting on the quality of service delivery. Certain facilities, equipment, structures and systems need to be in place to enable quality health care to be practised and delivered. The process of nursing service delivery is influenced by the nursing practitioners themselves and the way in which they practise health care which should be directed by clinical and managerial guidelines. There are several dimensions of quality which relate mainly to accessibility, equity, acceptability, efficiency, appropriateness/applicability, safety and professional/technical com- 
petency. These factors and dimensions need to be considered when the quality of nursing service management is assessed and evaluated.

This article focuses on the quality of nursing service management as one of the professional services, in accordance with the national accreditation programme of the Council for Health Service Accreditation of Southern Africa (COHSASA). The Council for Health Service accreditation was initiated in 1993 with the formulation of national standards by various expert groups, the implementation of these standards in six pilot hospitals who agreed to participate on a voluntary basis. The assistance of an international consultant was utilised during this period. COHSASA was registered as a notfor-gain organisation in October 1995. Towards the end of August 1998, 83 hospitals (16 public and 67 private) had entered COHSASA's hospital accreditation programme of which 45 have been awarded accreditation status and another 30 are due for the external survey during 1999. COHSASA represents a national collaborative effort between the state, private industry, consumers and health professionals. The programme aims to assist participating hospitals to comply with professional organisational standards which define systems and processes that the various professional bodies believe should be in place (Whittaker, 1998:10-14).

The Nursing Service is one of the professional services that are assessed within the hospital accreditation programme. It appears as if the nursing services compare very favourably with the other professional services - but the question arises: what is the quality of nursing service management in South African hospitals? The purpose with this research is to evaluate the quality of nursing service management within the COHSASA programme. A total of 45 nursing services have been evaluated (by means of an external survey) within the accreditation programme of which most $(\mathrm{N}=38)$ are part of private hospitals, three from the mine hospitals and the rest $(N=4)$ within public hospitals.

\section{Terminology}

\section{Quality}

Quality refers to the features or characteristics of excellence (stated in the form of standards and criteria) and the degree of compliance with pre-determined standards. Quality in this article refers to compliance with nursing service standards within the COHSASA accreditation programme.

\section{Nursing service management}

A nursing service is one of the professional services within a hospital. Nursing service management is the comprehensive nursing care service for the hospitalised patient consisting of the following elements in the accreditation programme: strategic planning, organisation, finance, human resource management, policies and procedures, facilities and equipment, nursing care and quality improvement.

\section{Accreditation}

Accreditation is a formalised process by which a government or non-government agency grants recognition to health care institutions which meet certain standards that require continuous improvement in structures, procedures and outcomes. It is usually voluntary, time-limited and based on periodic assessments by the accreditor and may, like certification, be used to achieve other desirable ends such as payment or funding (Donahue \& O'Leary, 1997:130). In South Africa, accreditation is a formalised process whereby national standards are set and compliance with them is evaluated by means of a sequential process comprising of internal evaluation by the health care service staff themselves during the preparatory phase, followed by an external evaluation by peers during the survey phase. A computerised calculation of results is done, followed by the validation of these results by a Technical Committee. On compliance with the standards, the accreditation status is awarded to the health care service by the Accreditation Board of the Council for Health Service Accreditation of Southern Africa (COHSASA). Accreditation certificates are valid for one to three years (Whitakker, 1998).

\section{Research Design}

A combined quantitative and qualitative research strategy is followed in accordance with the formalised accreditation process as developed and implemented by the Council for Health Service Accreditation of Southern Africa (COHSASA), consisting of an internal (pre-test) and external (post-test) evaluation/quality survey (Whittaker \& Muller 1998).

The trustworthiness of the evaluation survey is ensured by applying the principles as described by Lincoln and Guba (1985). The truth value of the results (credibility, applicability, confirmability and reliability) is increased by the following measures:

* a formalised accreditation system and process:

* prolonged engagement by the staff where the preparatory phase takes twelve to eighteen months and the nursing staff are continuously involved in the interpretation and implementation of the standards;

* the surveyors are professional and credible nursing experts who are familiar with the standards and spend at least three days in the hospital during a nursing service survey;

* a combination of evaluation strategies are used by the surveyors to assess compliance with standards;

* a structured verification process is followed by the surveyors during the external survey whereby the non/partially compliant, as well as those standards exceeding compliance, are verified by a second surveyor;

* a formalised process of internal and external validation of results is followed: a baseline assessment is conducted by the staff of the hospital, followed by a validation of these results by COHSASA staff, as well as continuous validation by the facilitator during the implementation (preparatory phase) of the standards;

* the external survey results are validated by the hospital staff with the opportunity of challenging any results and motivations which could result in a focus survey by the same or other surveyors;

* the external results are discussed and validated by the Technical Committee of COHSASA;

* the final results are discussed and validated by the Board of Directors of COHSASA:

* the standards are continuously updated to make provision for content validity of standards (the sixth revision process is almost finalised);

* a comprehensive computerised system is used for the calculation of results to exclude human error in this regard;

* international collaboration with the International Society of Quality in Health Care during the annual international conferences where the accreditation of health services is one of the interest groups and the principles, processes/ methods and problems related to accreditation are discussed.

The accreditation process follows a sequential and formalised process of a health service entering into a contractual agreement with COHSASA on a voluntary basis, a preparatory phase with a baseline self-evaluation, followed by the external survey phase. In the case of non-conformance with certain standards, a focus survey is conducted once the necessary remedial actions have been taken by the hospital management to verify compliance with the standards (Whittaker \& Muller, 1998).

\section{Preparatory phase}

After having entered into the formal 
agreement with COHSASA, a baseline survey is performed by the staff and validated by the COHSASA facilitator. The standards are then implemented in preparation for the external survey. A formalised process of facilitation is followed whereby the hospital is assisted with the implementation of the standards. The preparatory phase takes approximately twelve to eighteen months, depending on different factors impacting on the process and the capacity of the health care service to implement the standards. Approximately six weeks prior to the external survey, another internal evaluation is conducted by the hospital staff to determine the progress. The results of both the baseline and preexternal surveys are calculated and forwarded to the team of external surveyors.

\section{External survey phase}

Peer group evaluation is done by a team of external surveyors, based on the national standards and guidelines provided in terms of the accreditation programme. The surveyors not only provide an objective, external opinion regarding compliance with standards, but because of their experience they are also in a position to compare a specific health care facility with the larger group of health care organisations who use a set of standards, thereby providing the facility with information about how it compares within its peer group. The surveyors may also provide advice to the health care organisation when poor compliance has been achieved, which adds an educational and capacity building dimension to the accreditation process. The surveyors are trained in the principles of peer group evaluation and must complete at least two surveyor training sessions which include the beginners course as well as the advanced training programme where moc surveys are conducted. The surveyors also need to comply with the principles of credibility as experts in the particular fields being surveyed by them.

On completion of the external survey, a report is submitted by the surveying team to COHSASA, who finalises the report and calculation of results. A transparent process of validation if followed whereby the health service management gets the opportunity to comment or react to the report. The surveyors have to justify in writing any non/partial compliance, as well as those standards and criteria exceeding compliance. When there are discrepancies between the views of the surveyors and staff of the health care service on any ratings allocated or motivations given, this is verified by the COHSASA facilitators and sur- veyors. The report is then submitted to a Technical Committee who recom. mends the status of accreditation to the COHSASA Board. When there are serious limitations impacting on the quality of health service delivery, that particular hospital or health service gets six months to address the problems after which a focus survey is conducted. On compliance with the standards the accreditation status is awarded, which can range between one to three years.

\section{Quantitative and \\ qualitative analysis}

The standards and criteria are set in the form of a standards manual/evaluation instrument. Compliance with the standards are evaluated and a rating is allocated by the surveyor. This rating can be one of four: non-compliance, partial compliance, compliant and exceed compliance. A further qualitative evaluation is conducted by the surveyor in the case of non/partial-compliance with standards. The degree of seriousness is determined, which could be very serious, serious, moderate or mild. The impact of the non/partial compliancy is also determined by the surveyor which could be related to patient care, legality, staff and patient safety or efficiency. The surveyor therefore utilises both quantitative and qualitative methods of analysis. A computerised calculation (a statistical programme developed by COHSASA) is conducted by the programme administrators of COHSASA and the final rating could range between $0-40$ which is noncompliant, 41- 80 which is partially compliant, and $81-120$ as compliant. A score obtained higher than 120 implies that the standard exceeds compliance. A computerised weighting system is included in the statistical programme to ensure reliability of results. When the non/partial compliancy with a criterion is rated as very serious impacting on patient care or legality, this will impact on the results of that standard by means of a weighted deduction and calculation.

\section{Evaluation strategies}

The surveyor utilises different evaluation strategies to assess compliance with the standards and criteria. These strategies include individual and/or group interviews with service providers and patients, direct and indirect observation where the surveyor also follows the route of the patient (eg. from admission to discharge/transfer) involving the principle of a simulated patient experience. Document analysis also forms a significant part of the evaluation. The surveyor has to validate or cross check the compliance with standards between the different professional services (eg. whether the pharmaceutical drug control policies are implemented in the clinical units), as well as between the managerial, professional and support services (eg. whether the personnel policies are being implemented at operational or grass root levels). The external survey is conducted by at least three surveyors and the average time spent is three days (which includes the evaluation of night duty services when applicable).

\section{Core service elements}

The COHSASA standards comprise of core elements that are assessed in every health care institution or service. These core service elements relate to the management of the service, health and safety in accordance with the related legislation, resuscitation services, infection control and sterile services, the food, domestic, laundry and maintenance services, as well as the health record system. National standards and criteria for these core service elements are formulated by national expert groups and these standards have been reviewed once and the sixth revised set of standards is in the final phase of completion. This article does not focus on the discussion of results related to the core service elements, but describes the results of the nursing services as one of the professional services in a hospital

\section{Professional service}

\section{elements}

Apart from the core service elements that are assessed, the different professional service are also assessed. These include in-patient clinical/medical services (both medical and surgical), the anaesthetic or theatre services, the nursing and pharmaceutical services, as well as areas such as infection control. The different specialities that are offered in that particular health care service are also assessed, which could be critical care service, obstetric/maternity, psychology, laboratory, physiotherapy and many other services. National standards have been set by the national professional groups. The nursing service standards have been developed by a group of nursing service managers and experts.

\section{Health service standards:}

\section{common areas}

There are certain common areas in all the services which are assessed based on the national standards. These common areas include the philosophy/objectives of that service/speciality, the staffing composition, as well as the management and development of the staff, operational policies and procedures required in that speciality, the patient in- 
teraction and lastly the quality improvement programme. Although the focus of the accreditation programme at this stage is therefore on structure and process standards, the assessment of outcome will follow as soon as the different clinical indicators have been developed. The quality improvement programme does make provision, however, for that particular service to monitor the outcome of service delivery.

\section{Population, sampling and realisation}

A total of 83 hospitals have entered the COHSASA accreditation programme of whom 45 have been awarded accreditation status for the period 1995 . 1998 and many are in the final post-survey process prior to accreditation (Whittaker, 1998). All the nursing services that have been assessed by means of an external survey are included in this study which amounts to 45 of which 38 are in private hospitals, three in mine hospitals and four are in public hospitals. The inclusion criteria are as follows:

* hospitals that have entered into a formal agreement with COHSASA;

* the hospitals and nursing services who have completed the external survey where computerised results are available.

\section{Results}

The results of the evaluation survey on the quality of nursing service management in South African hospitals, are presented by means of an overall comparative performance where the quality of nursing service management is compared with other selected professional services, being resuscitation/casualty services, infection control, critical care, anaesthetic (theatre), management, medical and surgical in-patient services, as well as the pharmaceutical services. These professional services were selected from the 36 different professional services for which COHSASA has national standards,

98

96

94

92

90

88

86

84

82

80

78

Figure 1 : Overall comparative performance of selected professional services during the external surveys $(N=45)$

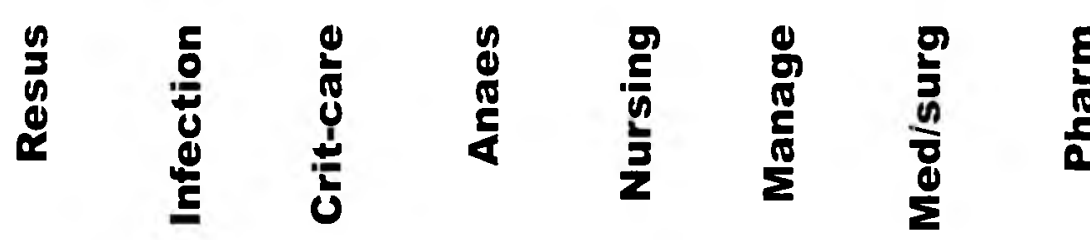

but based on the fact that they are assessed in all the hospitals (due to the fact that a limited amount of public hospitals have been evaluated, all the possible professional services are not included in these results because the private hospitals don't necessarily render all the services). The nursing service management is assessed in terms of the difference between the initial baseline assessments (pre-test) and the final external survey (post-test) results. This is followed by a general analysis of the quality of nursing service management in terms of their overall performance in the different standards applicable to the management of nursing services.

\section{Overall comparative performance}

The quality of nursing service management compares favourably with the other professional services (see figure one). The nursing services obtained an overall score of 95 . The resuscitation serv-

\section{Table 1 : Comparison between the baseline and external surveys : Nursing Services $(\mathbf{N}=45)$}

\begin{tabular}{|l|l|l|l|l|}
\hline Survey & Compliant & Partially C & Average score & Range \\
\hline Baseline survey & 18 & 28 & 64,3 & $42-92$ \\
\hline External survey & 45 & - & 95 & $69-118$ \\
\hline
\end{tabular}




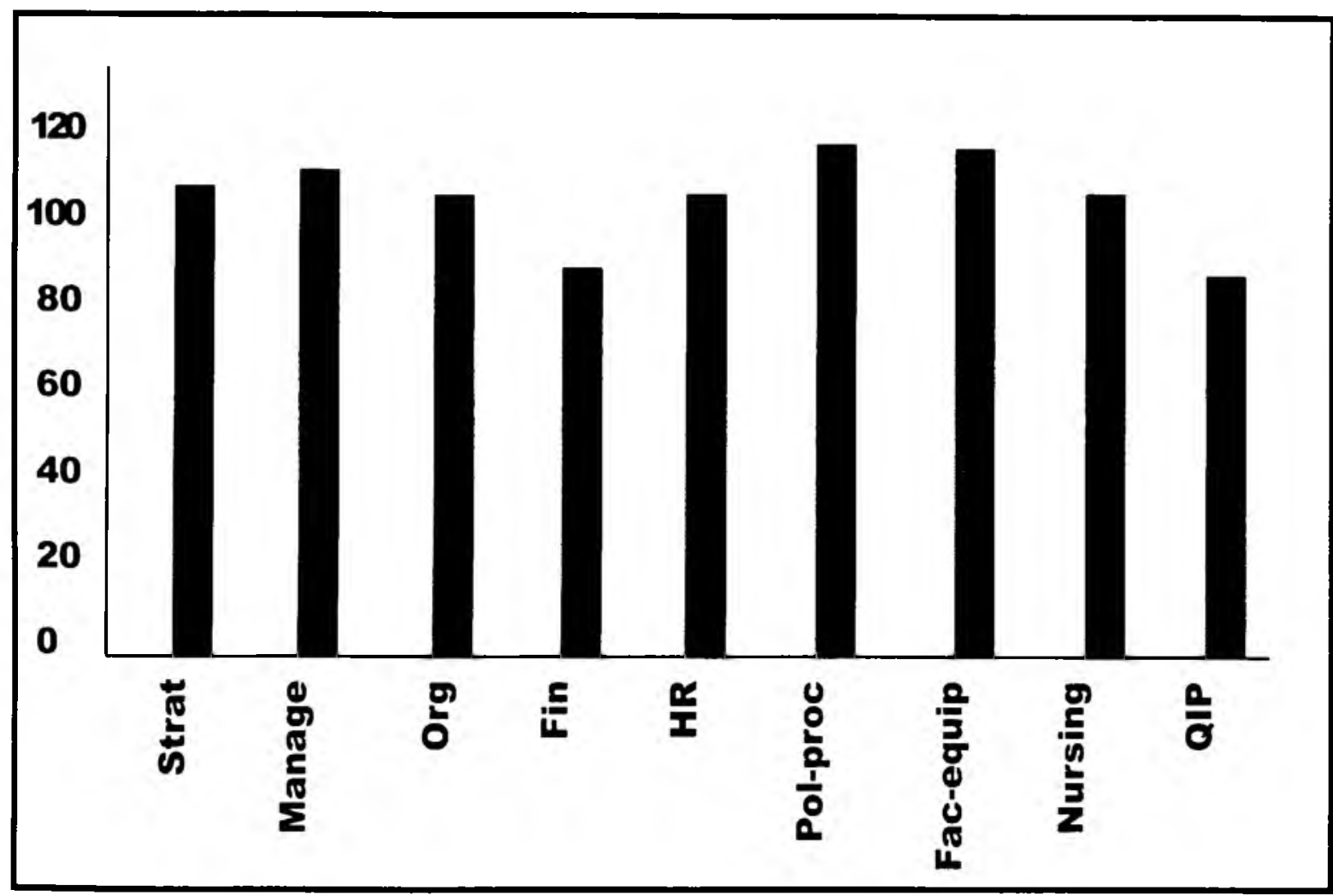

mum effectivity of nursing care and resources, which are reflected throughout the hospital.

This standard is sub-divided into ten different dimensions (see figure two) and the average compliance score of the subdivision is given in brackets: strategic planning (104) and management (107), organisation (103), financial managemen t (89), nursing human resource managemen t (102), policies and procedures (109), facilities and equipment

ices obtained the highest overall score of 99 , followed by the infection control services with a score of 97 and the critical care services with an average score of 96,5 . The overall average compliance score of management is 94 and the pharmaceutical services obtained a disappointing score of 86 . The anaesthetic services obtained the same score as the nursing service and the Medical and Surgical In patient services scored an average of 92 . These professional serv. ices are all compliant with the standards (the average score should range between 80-100 to comply with the standards).

\section{Nursing service \\ management performance:}

\section{comparison between baseline and external}

\section{surveys}

When the hospital has entered into a formal contractual agreement with COHSASA, the standards manual is given to the management. A COHSASA facilitator assists the staff with the interpretation of the standards and continuous empowerment regarding the principles of quality improvement is done. A hospital-based quality improvement committee is elected and one overall coordinator for the programme is identified and authorised as such. A baseline in- ternal assessment is conducted by the staff (pre-test), validated by the COHSASA facilitator, followed by the external assessment and survey approximately 18 months later.

Only 18 nursing services were compliant (obtained an overall score of at least 80) during the baseline survey as opposed to the external survey score of compliancy by all the nursing services $(N=45)$. The baseline assessment revealed an overall partial compliancy by 27 nursing services, with an average total score of 64,3 opposed to the external average score of 95 (compliant) by the nursing services in the external survey. The range of scoring during the baseline survey of $42-92$ in the different criteria has also improved significantly to 69-118 during the external survey (see table one). The statistical significance between the baseline and external survey assessments can not be accurately calculated due to the low frequency rate. The results do, however, show a remarkable improvement confirming the empowerment or capacity building advantage of the COHSASA programme.

\section{Overall nursing service performance}

The overall nursing service standard reads as follows: The nursing service management provides goal directed leadership and facilitates dynamic management processes for an integrated, co-ordinated and participative approach
(109), nursing care (105) and quality improvement programmes (73). It is clear that the nursing services $(N=45)$ are not compliant with the quality improvement standards and that there are limitations/problems related to financial management.

\section{a) Strategic plan}

A written strategic plan is required, with the mission statement, objectives and actions to achieve these objectives, as well as proof of a participative management approach being practised. The nursing services were mostly non-compliant with this standard during the baseline survey (score of 45), as opposed to an average score of 104 obtained during the external survey which reveals full compliance with this standard and related criteria. The principles of participative management are not always fully implemented though and it is also difficult for the external surveyor to assess this during the short survey period. The nursing service managers' participation in top management decision-making on strategic issues, also appear to be limited.

\section{b) Management}

This standard relates to the qualifications and experience of the nursing service manager, as well as her/his inputs and interaction with the top management of the hospital to ensure credible input by the nursing fraternity. The nursing services are compliant with this standard (average compliant score of 92 during 
the baseline survey and a score of 107 during the external survey), with highly professionally qualified nursing service managers in charge of the various nursing services. The quality of their input in top management decisions can, however, not be assessed through this accreditation programme.

\section{c) Organisation of the nursing service}

The nursing service is organised to ensure quality clinical nursing/midwifery care and cost effective management of resources. This standard is measured by means of six criteria relating to the following: a written organogram, the integration of the nursing service with other systems and services of the hospital, a system to ensure patient-focused nursing care with appropriate continuity thereof, professional supervision of patient care at all times, appropriate support services to enable the nursing staff to focus on nursing responsibilities and duties, as well as the utilisation of appropriate statistics to optimise nursing care and the utilisation of resources. An average compliant score of 103 was obtained for this standard during the external survey as opposed to a score of 76 obtained (partially compliant) during the baseline survey.

\section{d) Financial management}

The nursing manager is accountable for the financial management of the nursing service, in accordance with the financial system of the health care organisation. This standard is measured by means of four different criteria in relation to assessment and preparation of the nursing service budget, the monitoring of expenditure, a system of utilisation review and cost containment, as well as involvement in the overall financial management of the health care organisation as a member of top management. $A$ score of 89 was obtained in this standard during the external survey which reflects the lowest score of them all. This shows a slight improvement from the partially compliant baseline survey score of 76 .

\section{e) Human Resource}

\section{Management}

The nursing service manager is accountable for quality human resource management within the nursing service. This standard is measured in relation to a human resource strategy, staffing, selection and appointment, appropriate utilisation of staff, induction and orientation, staff development and education, staff appraisal and fair labour practices, including the principles of health and safety. A total of 33 criteria are used for assessment of compliance with this standard and an average score of 103 was obtained by the nursing services during the external surveys. The average baseline survey score for this standard was 74 (partially compliant).

\section{f) Policies and procedures}

There are written policies and procedures for the activities of the nursing service, compiled within the professionalethical framework of the nursing profes. sion, which reflect current standards of practice, regulations and the objectives of the health service. This standard requires that policies and procedures for the nursing service are in place in accordance with 28 criteria. An average compliant score of 109 was obtained in the external survey as opposed to a partially compliant score of 52 during the baseline survey. It is common to find the absence of written policies and procedures on commencement of the accreditation programme. This results in a very labour intensive process by the nursing service to get all the policies and procedures in place prior to the external survey. This also causes a lot of paper work for the service.

\section{g) Facilities and equipment}

A therapeutic environment is created and maintained in the nursing service to ensure safe nursing care in accordance with the legal requirements. Ten different criteria are used to ascertain compliance with this standard: the assessment and planning of facilities and equipment, a positive atmosphere in the units, a safe environment, accessibility, patient communication systems, patient privacy, the safety of beds, emergency alarms, patient comfort such as lighting, overbed tables and chairs, and the maintenance of equipment - both pro-active and reactive systems. A fairly high score of 109 was obtained for this standard during the external survey, revealing adequate compliance. The baseline survey score of 75 revealed deficiencies that were mainly in relation to the pro-active maintenance programmes.

\section{h) Nursing care}

Quality nursing care - appropriate, safe, legal and effective - is ensured in the nursing service. This is achieved by scientifically-based nursing practice in relation to the following: evidence-based nursing care, the execution of nursing care in accordance with the Scope of Practice Regulations of each nurse category, a nursing record system that is compliant with the legal principles, nursing care plans with appropriate and continuous evaluation of patient progress, appropriate management and recording of visits by multi-professional team mem- bers, patient education, timeous and appropriate referrals by the nursing staff and pre-discharge/transfer planning and management. A sub-standard on medication and treatment with 18 different criteria is used to assess the quality of medication management and administration by the nursing staff, in accordance with legal requirements. Quality emergency intervention is ensured in the nursing service by having the necessary emergency equipment in place with proof of proficiency in emergency treatment/abilities. Patient care in relation to the preparation of patients for diagnostic and surgical interventions is assessed, as well as the management of patients in accordance with the prescribed treatment regimens, policies and procedures. The continuity of patient care, specialised nursing care, and the management of ethical problems, are also assessed within this standard. An overall average partially compliant score of 69 was obtained during the baseline survey and a compliant score of 105 was obtained during the external surveys.

\section{i) Quality improvement}

A quality improvement programme is a formalised comprehensive programme focusing on the monitoring and evaluation of those interactions that impact on nursing care, based on written standards, with evidence of remedial action taking place to address deficiencies. A formalised quality improvement programme is maintained in accordance with 15 different criteria. These criteria focus on the full quality cycle (formulation of standards, monitoring/evaluation and remedial action) to be developed and implemented in the nursing service in a participatory and multi-disciplinary or collective manner. The total average partially compliant score for this standard during the external survey was only 73 - the lowest of all the scores. This does, however, show a remarkable improvement from a score of 42 which was obtained during the baseline surveys. The nursing staff still find it difficult, time consuming and expensive to have formalised quality improvement programmes in place. These programmes have to be driven by a very committed person.

\section{Conclusions}

The following conclusions are relevant: * the external survey scores were significantly higher than the baseline scores due to the process of facilitation during the preparatory phase, resulting in empowerment and capacity building;

* the highest scores during the external surveys were obtained in the standards relating to policies/procedures and facilities/equipment; 
* although compliant with a score of 89 , financial management by the nursing service managers is inadequate;

* the principles of quality improvement have not yet been fully implemented with a partially compliant score of 73 ;

* statistical analysis of the results (comparisons between the baseline and external survey results) is problematic due to the low frequency rate $(N=45)$.

\section{Concluding Remarks}

\section{and}

\section{Recommendations}

The following recommendations are made:

* statistical validation of the standards (content and construct validity);

* reliability tests to determine the reliability of the instrument and inter-rater reliability between surveyors;

* the impact of the COHSASA programme on the quality of nursing service management should be determined; * the development of quality indicators to be utilised by the various nursing services for comparative purposes;

* continuous revision of the standards and related criteria;

* continuous professional development of nursing service managers, unit managers and clinical nurses/midwives with regard to the various quality improvement activities, including the principles of total quality management.

Determining the quality of nursing service management is a lifelong process which requires commitment, perseverance and lots of energy by all the roleplayers. Once the health care organisation has committed itself to the accreditation process, the COHSASA facilitator has to manage the dynamics both the positive and negative dynamics. But it always remains an exhilarating experience!

\section{Acknowledgements}

The author would like to thank COHSASA for all the opportunities as being a facilitator and surveyor within the programme. COHSASA is also thanked for making the results available for publication purposes.

\section{References}

COHSASA. 1996. Standards manual. Pinelands: COHSASA.

COHSASA. 1995-1998. External survey reports. Pinelands: COHSASA (unpublished).

DONAHUE, K.T., \& O'LEARY, D.S. 1997. Evolving healthcare organization accreditation systems. International Hospital Federation 50th Anniversary Commemoration. Hospitals \& Healthcare - Past, Present and Future. IHF - Garnett Dickinson Ltd: South Yorkshire.

GUBA, E.G., \& LINCOLN, V.S. 1985. Naturalistic inquiry. London: Sage.

WHITTAKER, S. 1998. Executive Unit Report for the period May 1997 to August 1998. Pinelands: COHSASA (unpublished).

WHITTAKER, S., \& MULLER, M.E. 1998. Improving the quality of care in South African health care facilities. Hospital and Nursing Yearbook of Southern Africa. Cape Town: Engelhardt \& Co. Publishers. 